\title{
Photoaddition Reactions of 1,2-Diketone
}

\author{
Hea Jung Park ${ }^{1}$, Jung Soo Seo ${ }^{1}$, Ung Chan Yoon ${ }^{1 *}$, Dae Won Cho ${ }^{2 *}$ \\ ${ }^{1}$ Department of Chemistry and Chemical Institute for Functional Materials, \\ Pusan National University, Busan 609-735, Korea \\ ${ }^{2}$ Deparment of Chemistry, Yeungnam University, Gyeongsan, Gyeongbuk 712-749, Korea
}

\begin{abstract}
Photoaddition reactions between 1,2dicarbonyl compounds and silyl enol ethers in acetonitrile and benzene were explored. Irradiation of acetonitrile or benzene solutions containing 1,2-diketone, acenaphthalquinone, phenanthrene-quinone and silyl enol ethers is observed to promote the production of 1,4dioxenes, oxetanes, and $\beta$-hydroxyketone by the [4+2]cycloadditon, Paterno-Buchi processes, and SET promoted Claisen-type condensation. Among these competitive pathways leading to the generation of each types of products, SET promoted 1,4-dioxene and $\beta$-hydroxyketone formation are more favored regardless of solvent polarity.
\end{abstract}

In recent studies, we explored photochemical reactions of 1,2-diketone and silyl ketene acetals and showed that versatile $\mathrm{C}-\mathrm{C}$ or $\mathrm{C}-\mathrm{O}$ bond forming processes take place. On the basis of an analysis of the protoproducts presented previous study ${ }^{1}$, ground state/ excited state redox properties of 1,2-diketone electron acceptor ${ }^{2-3}$ and silyl ketene acetal electron donor ${ }^{4,5}$, and results of photoreactions of monoketone analogs ${ }^{4,6-8}$ give plausible mechanistic pathways for 1,2-diketone with silyl ketene acetals (Scheme 1). Single electron transfer (SET) - promoted or direct [4+2] cycloaddition $^{1,9}$, classical Paterno-Buchi [2+2] cycloaddition $^{1,4,10}$, and sequential SET-desilylation processescompete for deactivation of the 1,2-dicarbonyl excited state by the silyl ketene acetals. These respective processes generate ion radical pairs I and oxetanes II. Desilylation of I produces radical pairs V, which undergo coupling to form ketoester products VIII. Alternatively, radical and/or ionic coupling of ion radical pairs I produces biradicals IV or zwitterionic intermediates III, which are the precursors of the respective 1,4-dioxenes VII and oxetanes VI, the latter of which should easily convert to ketoesteres VIII.

In this study, as a continuing effort, we explored the photoaddition reactions of acenaphthenequinone/ phenanthrenequinone as 1,2-diketones 1-2 and dimethyl/monomethyl-substituted silyl enol ethers $3-4^{11-13}$ as silyl electron donors ${ }^{14}$ (Scheme 2).

*To whom correspondence should be addressed. E-mail: ucyoon@pusan.ac.kr Received February 1, 2012; accepted February 21, 2012
Scheme 1.

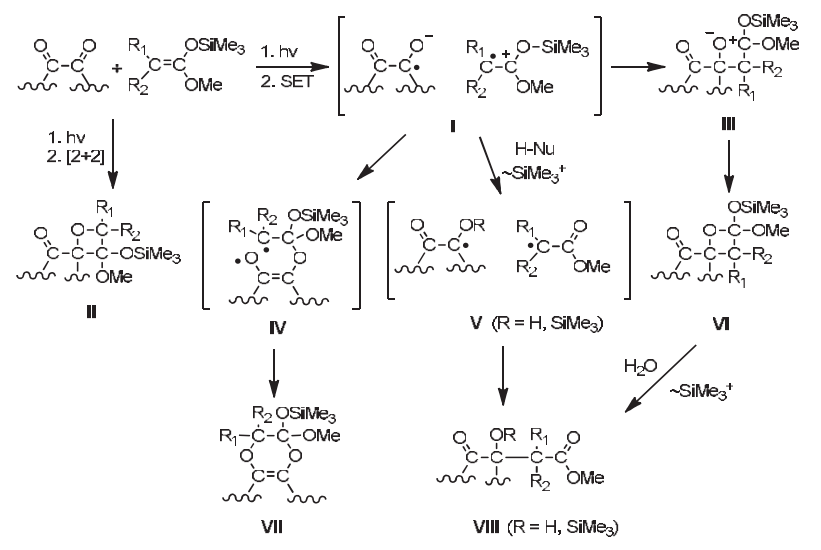

Scheme 2 .

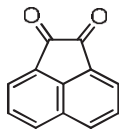

1

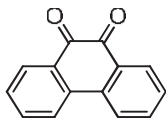

2
$\underset{\mathrm{R}_{2}^{\prime}}{\mathrm{R}}=\underset{\mathrm{H}}{\mathrm{C}_{\mathrm{H}}^{\prime}} \mathrm{OSiMe}_{3}$

$$
\begin{aligned}
& 3\left(R_{1}=R_{2}=M e\right) \\
& 4\left(R_{1}=M e, R_{2}=H\right)
\end{aligned}
$$

Photochemical reactions were performed by irradiation with Uranium glass filtered light $(\lambda>330 \mathrm{~nm})$ of acetonitrile or benzene solutions of $1-2$ (11 mM) and the $3-4$ (22 $\mathrm{mM})$.

Scheme 3.

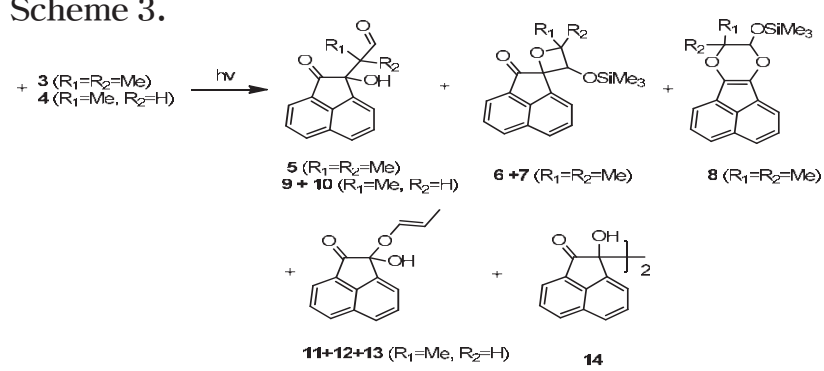

The products/yields arising from photoreactions of aromatic 1,2-diketone 1-2 with silyl enol ether 3-4are displayed in Scheme 3-4 and Table 1. Irradiation of acetonitrile solution of acenaphthenequinone (1) and dimethyl-substituted silyl enol ether 3 results in the formation of $\beta$-hydroxyketone $5(32 \%)$ as major and oxetanes $6+7^{15}$ as minor products $(4 \%, 2 \%)$. In benzene, both hydroxyketone 5 (22 \%) and 1,4-dioxene 8 (14\%) are major products, which are arisen by SET-promoted 
addition pathway. Though the yields of oxetanes are quite small, Paterno-Buchi type [2+2] cycloaddition reaction seem to take place. When replaced to monomethyl substituted silyl enol ether 4 for photoreaction with 1 , SETdesilylation process took place predominantly to form $\beta-$ hydroxyketone $9-10^{14}$ and $\alpha$-vinyloxy $-\alpha$-silyloxyketone $11-13^{14}$ along with minor amounts of the dimer $14^{1}$ in both acetonitrile and benzene solvents. Interestingly, no PaternoBuchi [2+2] cycloadducts were found in the photoreaction of 1 and relatively electron-deficient silyl enol ether 4 .

Table 1. Photoreactions of 1,2-diketones 1-2 and silyl enol ethers 3-4.

\begin{tabular}{ccccc}
\hline Reactant & Solvent & $\begin{array}{c}\text { Reaction } \\
\text { Time } \\
(\mathrm{min})\end{array}$ & $\begin{array}{c}\text { Conversion } \\
(\%)\end{array}$ & ${\text { Product }(\% \text { yield })^{\mathrm{a}}}^{2}$ \\
\hline $1+3$ & $\mathrm{CH} 3 \mathrm{CN}$ & 30 & 72 & $5(32), 6(4), 7(2), 8(2)$ \\
$1+3$ & Benzene & 40 & 68 & $5(22), 6(4), 7(3), 8(14)$ \\
$1+4$ & CH3CN & 90 & 96 & $9(21), 10(21), 11(2), 12(33)$ \\
$1+4$ & Benzene & 90 & 95 & $9(15), 10(15), 11(3), 12(28)$ \\
$2+3$ & CH3CN & 40 & 77 & $13(3), 14(9)$ \\
$2+3$ & Benzene & 50 & 73 & $15(27), 16(59)$ \\
$2+4$ & CH3CN & 50 & 87 & $17(8), 18(36), 19(36)$ \\
$2+4$ & Benzene & 60 & 90 & $17(34), 18(24), 19(24)$ \\
& & & &
\end{tabular}

${ }^{\text {aY }}$ ields are determined based on consumed 1,2-diketones

Photolysis of phenantrenequinone (2) with silyl enol ethers 3-4 give rise to different product distribution pattern as compared with those produced from photoreaction of 1 and 3-4. For example, regardless of the solvent used, photoreactions of 2 with silyl enol ethers $3-4$ lead to the formation of 1,4-dioxenes as sole products. (Table 1 and Scheme 4).

\section{Scheme 4.}

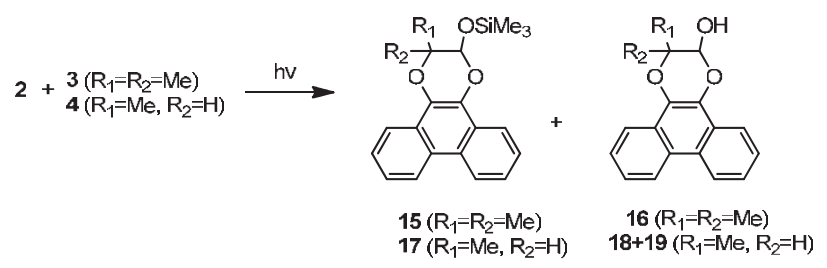

Two major conclusions can be drawn from the results shown in Table 1. First, SET promoted deactivation pathway is major or predominant in the photoreactions of 1,2-diketone and silyl enol ethers. Second, solvent polarity is not significant factor that governs the reaction pathways, which are found in previous studies. ${ }^{1,4,13}$
Even though more studies are necessary to investigate the substituent's effect of silyl enol ether and reaction pathways in detail about the photoreaction of 1,2-diketones and silyl enol ethers, observations made in this study show that SET promoted pathways take place highly efficiently and regioselectively.

\section{Acknowledgement}

This study is supported by 2011 Yeungnam University research grant (D. W. Cho) and the New \& Renewable Energy program of the Korea Institute of Energy Technology Evaluation and Planning (KETEP) grant (No.20103020010050) funded by the Ministry of Knowledge Economy, Republic of Korea (U. C. Yoon).

\section{References}

1. Cho, D.W.; Lee, H-.Y.; Oh, S.W.; Choi, J.H.; Park, H.J.; Mariano, P.S.; Yoon, U.C. J. Org. Chem., 2008, 73, 4539

2. Burkoth, T.L.; Ullman, E.F. Tetrahedron Lett., 1970, 11, 145

3. Maruyama, K.; Ono, K.; Osugi, J. Bull. Chem. Soc. Jpn., $1972,45,847$

4. Yoon, U.C.; Kim, M.J.; Moon, J.J.; Oh, S.W.; Kim, H.J.; Mariano, P.S. Bull. Korean Chem. Soc., 2002, 23, 1218

5. Renaud, R.N.; Berube, D.; Stephens, C.J. Can. J. Chem.,1983, 61, 1379.

6. Fukuzumi, S.; Fujita, M.; Otera, J.; Fujita, Y. J. Am. Chem. Soc., 1992, 114, 10271

7. Sato, T.; Wakabayashi, Y.; Otera, J.; Nozaki, H.; Fukuzumi, S. J. Am. Chem. Soc., 1991, 113, 4028

8. Mizuno, K., Takahashi, N.; Nishiyama, T.; Inoue, H. Tetrahedron Lett., 1995, 41, 7463

9. Rubin, M.B.; LaBarge, R.G. J. Org. Chem., 1966, 31, 3283

10. Anold, D.R. In Advances in Photochemistry Noyes, W.A., Hammond, G.S., Pitts, J.N., Eds.; Interscience Publishers: New York, 1968; Vol. 6

11. Gassman, P.G.; Bottorff, K.J. J. Org. Chem., 1988, 53, 1097

12. Pandy, G.; Karthikeyan, M.; Murugen, A. J. Org. Chem., 1998, 63, 2867

13. Oh,S.W.; Kim, J.Y.; Cho, D.W.; Choi, J.H.; Yoon, U.C. Bull. Korean Chem. Soc., 2007, 28, 629

14. Cho, Dae Won; Yoon, Ung Chan; Mariano, Patrick S. Acc. Chem. Res., 2011, 44, 204

15. Diastereomeric mixtures were formed due to the generation of stereocenter. Yields were determined based on integration ratios of ${ }^{1} \mathrm{H}-\mathrm{NMR}$ 